\title{
Induction of Osteosarcoma and Biochemical Effects in Rats Treated with Benzopyrene
}

\author{
Paniagua Pérez $R^{1 *}$, Franco y Bourland $R^{1}$, Madrigal Bujaidar $E^{2}$, Álvarez González $I^{2}$, Velasco Mora $O^{1}$, \\ Martínez Coria $E^{3}$, Araujo Monsalvo $V^{4}$, Domínguez Hernández $V^{4}$, González-Cortez $\mathrm{J}^{1}$, Straface $\mathrm{JI}^{5}$ and \\ Luna Méndez Martín?.
}

${ }^{1}$ Servicio de Bioquímica, INRLGII, Mexico

${ }^{2}$ Laboratorio de Genética-ENCB-IPN, Mexico

${ }^{3}$ Servicio de Tomografía Computada-INRLGII, Mexico

${ }^{4}$ Servicio de Biomecánica-INRLGII, Mexico

${ }^{5}$ Universidad Anahuac, Méx, Mexico

\begin{abstract}
Osteosarcoma accounts for $20 \%$ of all sarcomas, affects children and young adults, usually originating in lower limb bones and possibly ending in amputation. The murine models identify the molecular and pathophysiological basis of diseases and allow the development of new therapies for their treatment. Benzopyrene (BZP) is an aromatic polycyclic hydrocarbon, reported as a potent cancer inducer. The objective of this work was to standardize a model of bone carcinogenesis in rats. The weight of the rats was recorded, blood samples were taken in order to perform genotoxicity studies and to determine erythrocyte sedimentation rate (ESR), alkaline phosphatase (AF) and lactic dehydrogenase (LDH). In the ninth week, the animals were sacrificed; femurs, tibiae, liver and lungs were extracted for histopathological study. When compared with initial treatment results, a decrease in weight was observed (28\%). The frequency of micronuclei increased significantly $(33.73 \pm 0.53)$. The frequency of polychromatic erythrocytes in the ratio erythrocytes normochromic, PCE/ ENC, decreased significantly $(2.17 \pm 0.31)$. Increased ESR, AF and LDH $(114 \%, 74 \%, 67 \%)$. The histological study showed the presence of cellular and osteoid atypia in all the rats treated and the formation of tumors in the femur administered with BZP. The lungs and liver did not show histopathological changes. It was concluded that BZP can induce osteosarco$\mathrm{ma}$, it is highly genotoxic and cytotoxic, its use can serve as an experimental model in the chemical induction of osteosarcoma and can be useful in research involving this condition as a basic pathology.
\end{abstract}

Keywords

Osteosarcoma, Benzopyrene, Sprague Dawley rat, Murine model

\section{Introduction}

Osteosarcoma is a primary malignancy, derived from bone mesenchyme and typically forms osteoid tissue or immature bone. It typically occurs during the adolescence, during the growth stage. It is the most common solid bone primary tumor, constituting [1] approximately $20 \%$ of primary bone sarcomas (American Cancer Society, 2018). Each year between 400 and 1000 new cases are diagnosed in the United States $[2,3]$, which means an incidence of $8 / 1,000,000$ in the general population. It is considered a juvenile disease as 7.5 out of every 10 cases appear in patients under 25 years of age [4]. Most cases in older patients are secondary sarcomas, that is, sarcomas arising as a complication of preexisting bone diseases (Paget's disease, chronic osteomyelitis, chronic bone infarcts) or on previously irradiated tissues. It is one of the few tumors that start in the bones and metastasize to other parts of the body [5].

Osteosarcoma is considered by a complex of resistance to conventional treatments. Currently there is no effective method to prevent this type of cancer. The treatment of

*Corresponding author: Rogelio Paniagua-Pérez, INRLGII: Av México-Xochimilco 289, Col. Arenal de Guadalupe, Tlalpan, CP14389, Mexico

Accepted: September 14, 2019

Published online: September 16, 2019

Citation: Paniagua PR, Franco BR, Madrigal BE, et al. (2019) Induction of Osteosarcoma and Biochemical Effects in Rats Treated with Benzopyrene. J Orthop Rheumatism 3(1):62-70 
osteosarcoma includes chemotherapy, followed by surgery (amputation or salvatage surgery) and post-surgical chemotherapy. Despite significant advances in the treatment of osteosarcoma, the prognosis of patients with metastases remains poor, with a $55 \%$ overall survival after surgery and aggressive chemotherapy [6,7].

\section{Animal models}

The animal models used in bone tissue research are as diverse as the materials and repair strategies. Generally, and as in other areas of science, animal studies are initiated in models such as the mouse or the rat, followed by rabbits, pigs and sheep. Most of the studies focus on medium and large animals, because the surgery is complex and requires a large area in order to be performed and the results obtained in these cases are more easily extrapolated to a possible clinical use. Regarding models of musculoskeletal tissue injury, both critical injury models (lesions that are not repaired spontaneously) and noncritical models (spontaneous healing lesions) are used [8]. The anatomical locations of these defects depend on the objective of the study. In this sense, the most common are injuries and osteotomies in long bone (femur, tibia, humerus and radius), skull, lumbar injuries and lesions in the maxillofacial region. There is some controversy when comparing results obtained in different animal models. This is because, in some cases, compounds that seem to work in small animals do not work in larger animals. Therefore, it is considered of great importance the correct choice of the study material, the type of injury to be performed and the animal model chosen [9].

\section{Murine cancer induction models}

Since the beginning of the last century to the present day, murine models have contributed to the understanding of the pathogenesis of many diseases and the development of new therapies. The current trend of biomedical research suggests that in the near future the availability of murine models will be greatly enhanced by the large number of genetic manipulation techniques and existing chemical mutagenesis projects. Therefore, the use of these models will be essential for the functional study of the sequences obtained from the sequencing projects of the human and murine genome $[10,11]$.

The use of murine models is because these models help in the understanding of the pathogenesis of many diseases and the development of therapies to replace the defective function of a given gene. In experimental medicine, the rodent is a model organism that offers many advantages over other genetic models such as the fly Drosophila fly, the Caenorhabditis elegans benatode, among others $[12,13]$. These advantages are:

- Being a mammal, a large part of its biochemical processes are similar although not identical to human.

- They have a very short gestation time, they are very prolific and they adapt easily to life in bioterium, which allows to control the environmental variables in the experiments.
- After human, they are the most studied species in a genetic point of view

- There are a large number of genetically defined lines, such as consanguineous and congenic lines, in addition to hundreds of mutations and a large number of available chromosomal rearrangements.

- It is the only animal that has efficient systems for cultivating pluripotent embryonic cells (ES cells), which allows the realization of targeted mutations (constitutive and conditional KO mice).

Some models reported in the literature for OS development are the following: An animal model for human OS was established in newborn Syrian golden hamsters, injecting cultured human OS cells adjacent to the femur, all animals developed OS and pulmonary metastases with a 36-day survival mean $[8,14]$. Another model was developed with tibial intramedullary injections of Moloney murine sarcoma virus in three strains of neonatal inbred rats, 10 days later they presented highly malignant tumors, producing mortality in all treated rats [10]. Another group of researchers induced OS with virus using the lymphocyte microtoxicity test, with intratibial injection of Moloney murine sarcoma virus. $73 \%$ of the injected animals progressed to OS and caused pulmonary metastasis with survival was not longer than 2 months [15]. However, these models have disadvantages; mortality is high in each of the models used benzopyrene.

\section{Benzopyrene}

Benzopyrene (BZP) is a potentially carcinogenic polycyclic aromatic hydrocarbon (PAH). The high content of BZP in some foods (nuts, sausages, chorizo, spices, pizzas, wood oven bread, grilled meats, roasted coffee) is due to its elaboration process that involves incomplete combustion processes, it can also be found in tobacco. The BZP is produced by condensation of five benzene rings during combustion processes at temperatures of 300 to $600{ }^{\circ} \mathrm{C}$. Since 1775 the British doctors Pott and Hill, observed high incidence of scrotal cancer in the personnel in charge of the cleaning of chimneys (chimney sweeps) [16]. About a hundred years later, similar findings were reported in Germany and Scotland, among workers in the coal tar and paraffin industry. These observations led to the conclusion that petroleum and coal derivatives contained substances capable of inducing tumors. confirmed in 1918, when Japanese researchers Yamagiwa and Ichikawa showed that tar applied to the skin of rabbits induced cancer [17]. Similar findings in rats were documented in 1920, in England by Kennaway reported by Hugues. However, since tar and soot are mixtures of various substances and the isolation of the possible chemical compounds responsible for such results was complex, it was not until 1920 that isolated PAHs of tar were identified as possible responsible for producing tumors in the skin in mice [18].

In 1931, one of the PAHs, benzopyrene (BZP), was isolated from the carbon, in the same year it was synthesized and it was demonstrated that it was responsible for the production of cancerous tumors in experimental animals. It was also found in coal tar, tar and soot [19], one of the first carcin- 
ogens clearly identified. In epidemiological studies on workers exposed to coke ovens, during the industrial coal coking process, asphalt works, smelters and aluminum facilities were found to have a higher rate of lung cancer than those who did not perform those work activities, what was attributed to the exposure to PAH [20]. Subsequently, investigations revealed that PAHs were also found in foods consumed by humans [21]. BZP apparently acts on the K-Ras gene, causing a mutation in a specific area of the gene that can be crosschecked in the DNA of patients with lung cancer. This finding not only serves to determine that tobacco is carcinogenic, but also can be useful to develop new therapeutic strategies based on the specific information available for DNA damaged by cancer [22].

\section{Material and Methods}

\section{Animals}

10 male Sprague Dawley rats were used, donated by the National School of Biological Sciences, with an average weight of $180 \mathrm{~g}$, divided into 2 groups and kept in polycarbonate boxes. The environmental conditions of the farm were: Light/dark period of $12 / 12$ hours; temperature of $22 \pm 2{ }^{\circ} \mathrm{C}$ and relative humidity of $60-70 \%$, with access to food (Purina) and water.

\section{Reagents}

Benzopyrene (Sigma-Aldrich), (Sigma-Chemicals, 99\% purity).

\section{Description of the procedures: Induction of OS with BZP and BS administration}

Lesions were induced by perifemorally administration every 24 hours for 30 days at a dose of $20 \mathrm{mg} / \mathrm{kg}$ BZP (Sigma-Aldrich), dissolved in dimethylsulfoxide, the volume of administration was $0.3 \mathrm{~mL}$. Group 1 is the negative control group who will be administered in the distal portion of the right femur in a perifemoral injection and in three points, a daily administration of $0.3 \mathrm{ml}$ of dimethylsulfoxide (vehicle of BZP) for 30 days. Group 2 is the positive control group who were administered in the distal portion of the right femur in perifemoral injection and in three points, a daily administration of $20 \mathrm{mg} / \mathrm{kg}$ of BZP diluted in dimethylsulfoxide for 30 days, 7 days of rest were left (without any treatment) and later they were sacrificed for their study.

\section{Morphological evaluation and obtaining blood samples and animal sacrifice.}

1. From day 0 , the weight of the rats was recorded daily.

2. On day 0 and weekly for 4 weeks blood samples (two drops) were obtained from the end of the tail making a small cut $(1 \mathrm{~mm})$, to perform a blood smear for studies of genotoxicity and cytotoxicity.

3. From the end of the first week after the pharmacological manipulation and until the slaughter of the rats, the condition of the treated femurs was evaluated.

4. At week 0 and every three weeks, blood samples $(1 \mathrm{~mL})$ were taken from the mandibular and/or retro-orbital vein to determine sedimentation rate (Westergreen method), C-reactive protein (ELISA), alkaline phosphatase and lactic dehydrogenase (colorimetric analysis).

5. For the procedures where the animals needed be sedated, it was done using an ether impregnated cotton placed in a wide-mouthed bottle, in which the studied animal was introduced as long as necessary in order for it to reach a sedated state.

At the end of the ninth week the animals were euthanized, by cervical dislocation. At the time of surgically opening the abdomen, a macroscopic evaluation of the rat's organic state was made, with special attention to the lung, liver, kidney, spleen and intestine. The femurs, tibias, lungs and liver were removed and washed with a shock absorber. They were then in a $10 \%$ formalin buffer, and the samples were fixed and maintained at $4^{\circ} \mathrm{C}$ until their histological study.

\section{Histopathological study of femur and rat tibia}

Once the femurs and tibias of the rat were obtained, each sample was washed with a shock absorber, later it was fixed in $10 \%$ buffered formalin, keeping them overnight at a temperature of $4{ }^{\circ} \mathrm{C}$, for 12 hours. The femurs and tibias were placed in a decalcifying solution ( $5 \%$ nitric acid for 96 hours). The bone was neutralized by introducing it in a $10 \%$ carbonate solution and washed with running water for 15 minutes. The samples were embedded in paraffin. The histological preparations were immersed in xylol to eliminate excess paraffin. Subsequently, histological sections were made in a rotary microtome type Minot. The tissue was cut until reaching intact tissue in 5 micron slices, and then placed with a brush in a flotation bath. The lamellae were marked with the number corresponding to the sample. The selection and placement of the cut on the slide was made. The excess water was drained in the histological preparations and fixed with heat (plate with thermostat at $56-58{ }^{\circ} \mathrm{C}$ ). The dewaxing of the histological sections was done in an oven or stove at $60^{\circ} \mathrm{C}$ for $30 \mathrm{~min}$. Then they went through a series of alcohols in a decreasing concentration to rehydrate the sample $\left(100^{\circ}, 95^{\circ}\right.$ and $\left.70^{\circ}\right)$. They were washed in water to remove excess alcohol. They were immersed in hematoxylin for 10 minutes, washed in water to eliminate excesses and rapidly passed through acid alcohol. A wash was performed again, they were immersed for 30 seconds in eosin. They went through another series of alcohols, this time in increasing order $\left(70^{\circ}, 95^{\circ}\right.$ and $100^{\circ}$ ). to dehydrate the sample, to achieve the assembly with a glue not soluble in water. Finally, they were allowed to soak 10 minutes in xylol, before making the final assembly and observation under a microscope $[15,23]$.

\section{Evaluation of genotoxicity and cytotoxicity in peripheral blood using Giemsa stain}

Once the blood samples were obtained from the tail of the rat, they were placed on perfectly clean slides and blood smears were made. For the staining of the samples, as a first step, they were fixed with methanol, submerging them for 
Citation: Paniagua PR, Franco BR, Madrigal BE, et al. (2019) Induction of Osteosarcoma and Biochemical Effects in Rats Treated with Benzopyrene. J Orthop Rheumatism 3(1):62-70

5 minutes, after which they were washed with tap water and stained for 18 minutes in $4 \%$ Giemsa stain in phosphate buffer $\mathrm{pH} 6.8$, plates were observed under the immersion microscope. The polychromatic erythrocytes (EPC) stained violet and the normochromic erythrocytes (ENC) stained blue. The micronuclei were observed in an intense violet color. To evaluate the cytotoxicity, the relationship between the number of EPN and ENC was determined. The account was made in 2000 cells per group at the established times and the amount of micronucleated normochromic erythrocytes was determined to evaluate genotoxicity $[24,25]$.

\section{Histopathological study of lung and liver}

The organs were placed in $10 \%$ formaline during 24 hour. After being embedded in parafin, the tissues where cut in slices from 2 to $4 \mathrm{~mm}$ thick. They were submerged in xilol in order remove excess parafin. Then they were sequentially submerged in decreasingly concentrated alcohol in order to rehydrate $\left(100^{\circ}, 95^{\circ}\right.$ and $\left.75^{\circ}\right)$. They were washed with running water to remove excess alcohol, then submerged in hematoxilin for 10 minutes, washed with running water, rapidly passed through acid alcohol, and finally submerged in eosin
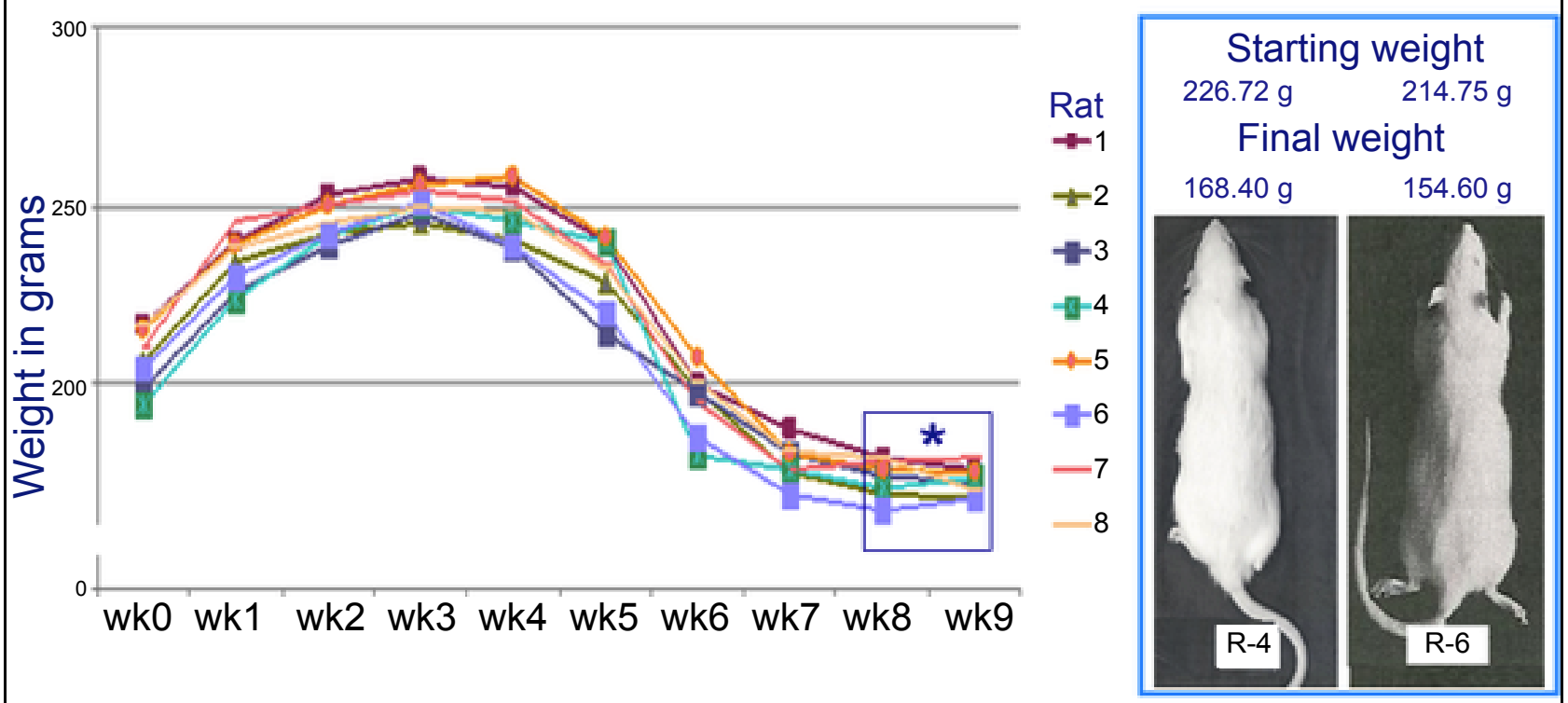

Graph 1: Weekly (wk) weight of rats (g) after benzopyrene (BZP) administration.

Statically significant difference between starting and ending weight. ANOVA, student T test $p<0.05$. The values correspond to grams.

Table 1: Frequency of micronucleus in rats $(\mathrm{R})$ treated with benzopyrene.

\section{Frequency of micronucleus}

$\bar{X} \pm$ d. e.

\begin{tabular}{|c|c|c|c|c|c|c|c|}
\hline Week > & 0 & 1 & 2 & 3 & 4 & 5 & 6 \\
\hline $\mathrm{R}-1$ & $1.13 \pm 0.16$ & ${ }^{*} 18.26 \pm 0.26$ & ${ }^{*} 19.3 \pm 0.29^{*}$ & ${ }^{*} 25.4 \pm 0.3^{*}$ & ${ }^{*} 20.5 \pm 0.22^{*}$ & ${ }^{*} 27.4 \pm 0.61^{*}$ & *30.5 $\pm 0.41^{*}$ \\
\hline $\mathrm{R}-2$ & $1.5 \pm 0.008$ & ${ }^{*} 19.8 \pm 0.36$ & ${ }^{*} 26.8 \pm 0.17$ & *25.0 0.12 & ${ }^{*} 24.4 \pm 0.38$ & ${ }^{*} 28.0 \pm 0.19$ & *29.5 \pm 0.18 \\
\hline $\mathrm{R}-3$ & $2.0 \pm 0.23$ & ${ }^{*} 19.3 \pm 0.35$ & ${ }^{*} 17.7 \pm 0.52$ & ${ }^{*} 29.76 \pm 0.11$ & ${ }^{*} 28.16 \pm 0.21$ & ${ }^{*} 29.76 \pm 0.11$ & ${ }^{*} 28.16 \pm 0.21$ \\
\hline$R-4$ & $1.0 \pm 0.12$ & "20.0 0.93 & ${ }^{*} 23.5 \pm 0.44$ & ${ }^{*} 26.83 \pm 0.61$ & ${ }^{*} 23.83 \pm 0.56$ & ${ }^{*} 31.43 \pm 0.41$ & *33.6 \pm 0.59 \\
\hline$R-5$ & $1.74 \pm 0.21$ & ${ }^{*} 22.0 \pm 0.63$ & " $18.6 \pm 0.19$ & ${ }^{*} 28.5 \pm 0.24$ & ${ }^{*} 27.5 \pm 0.34$ & ${ }^{*} 28.9 \pm 0.29$ & ${ }^{*} 32.5 \pm 0.13$ \\
\hline $\mathrm{R}-6$ & $1.14 \pm 0.32$ & "19.1 \pm 0.38 & ${ }^{*} 17.33 \pm 0.61$ & ${ }^{*} 25.38 \pm 0.33$ & ${ }^{*} 27.36 \pm 0.32$ & ${ }^{*} 30.38 \pm 0.30$ & "31.31 \pm 0.32 \\
\hline$R-7$ & $1.4 \pm 0.18$ & ${ }^{*} 21.8 \pm 0.55$ & ${ }^{*} 25.7 \pm 0.16$ & "28.4 \pm 0.16 & ${ }^{*} 29.4 \pm 0.39$ & ${ }^{*} 29.9 \pm 0.71$ & "31.8 0.77 \\
\hline$R-8$ & $1.2 \pm 0.22$ & ${ }^{*} 21.0 \pm 0.13$ & ${ }^{*} 26.1 \pm 0.32$ & ${ }^{*} 27.86 \pm 0.61$ & ${ }^{*} 31.02 \pm 0.55$ & ${ }^{*} 30.86 \pm 0.62$ & *33.73 \pm 0.53 \\
\hline
\end{tabular}

*Statistically significant difference with respect to week 0 , ANOVA and Student T test, $p=<0.005$; The frequency of erythrocytes was counted in 3000 cells per rat. 
Citation: Paniagua PR, Franco BR, Madrigal BE, et al. (2019) Induction of Osteosarcoma and Biochemical Effects in Rats Treated with Benzopyrene. J Orthop Rheumatism 3(1):62-70

for 30 seconds. They were then dehydrated by sequentially submerging in increasingly concentrated alcohol $\left(75^{\circ}, 95^{\circ}\right.$ and $100^{\circ}$ ). in order to be mounted in the lamellae with non hydrophilic glue. They were finally soaked with xilol for 10 minutes before finalizing the mounting, and observes in the microscope [18].

\section{Results}

A decrease in weight was observed up to $28 \%$ by the sixth week, relative to the weight at the start of the treatment (Graph 1). The frequency of $\mathrm{MN}$ increased significantly (33.73 \pm 0.53 ) when BZP was administered, indicating that BZP is highly genotoxic (Table 1 ). The frequency of polychromatic erythrocytes in the EPC/ENC ratio decreased significantly when benzopyrene was administered
$(2.17 \pm 0.31)$, indicating high cytotoxicity (Table 2$)$. In the end, $74 \%$ increase in alkaline phosphatase (AF) was observed in the sixth week relative to the start of the trial (Graph 2), which indicates that the high activity of oteoclasts could have generated this increase. The LDH was increased up to $67 \%$ compared to the initial values (Graph $3)$. The VSG showed an increase of up to $114 \%$ compared to the initial values of the trial (Graph 4). The histological study showed the presence of cellular and osteoid atypia in all treated rats and the formation of tumors in the femur administered with BZP (Figure 1). The lungs and liver did not show histopathological changes.

\section{Discussion}

\section{Experimental studies in animals on benzopyrene}

Table 2: The frequency of polychromatic erythrocytes (PE) in the relation with erythrocytes normochromic (NE) in rats (R) treated whit benzopyrene.

\begin{tabular}{|c|c|c|c|c|c|c|c|}
\hline \multicolumn{8}{|c|}{$\begin{array}{l}\text { Frequency of erythrocytes polychromatics } \\
\bar{X} \pm \text { d. e. }\end{array}$} \\
\hline Week & 0 & 1 & 2 & 3 & 4 & 5 & 6 \\
\hline $\mathrm{R}-1$ & ${ }^{*} 21.13 \pm 0.26$ & ${ }^{*} 10.13 \pm 0.23$ & ${ }^{*} 5.10 \pm 0.14$ & ${ }^{*} 4.5 \pm 0.08$ & ${ }^{*} 3.5 \pm 0.15$ & ${ }^{*} 3.0 \pm 0.13$ & ${ }^{*} 2.5 \pm 0.16$ \\
\hline $\mathrm{R}-2$ & ${ }^{*} 19.5 \pm 0.28$ & ${ }^{*} 10.8 \pm 0.46$ & ${ }^{*} 6.8 \pm 0.17$ & ${ }^{*} 5.0 \pm 0.42$ & ${ }^{*} 4.4 \pm 0.38$ & ${ }^{*} 3.8 \pm 0.07$ & ${ }^{*} 3.0 \pm 0.22$ \\
\hline$R-3$ & ${ }^{*} 20.0 \pm 0.48$ & ${ }^{*} 9.3 \pm 0.43$ & ${ }^{*} 7.7 \pm 0.52$ & ${ }^{*} 5.16 \pm 0.11$ & ${ }^{*} 4.16 \pm 0.21$ & ${ }^{*} 3.5 \pm 0.52$ & ${ }^{*} 2.17 \pm 0.31$ \\
\hline $\mathrm{R}-4$ & ${ }^{*} 21.0 \pm 0.12$ & ${ }^{*} 10.0 \pm 0.19$ & ${ }^{*} 6.5 \pm 0.44$ & ${ }^{*} 4.83 \pm 0.61$ & ${ }^{*} 3.83 \pm 0.56$ & ${ }^{*} 2.5 \pm 0.41$ & ${ }^{*} 2.83 \pm 0.52$ \\
\hline$R-5$ & ${ }^{*} 21.3 \pm 0.57$ & ${ }^{*} 12.0 \pm 0.43$ & ${ }^{*} 8.3 \pm 0.19$ & ${ }^{*} 6.5 \pm 0.24$ & ${ }^{*} 4.5 \pm 0.34$ & ${ }^{*} 2.3 \pm 0.14$ & ${ }^{*} 2.5 \pm 0.33$ \\
\hline$R-6$ & ${ }^{*} 20.14 \pm 0.05$ & ${ }^{*} 9.1 \pm 0.37$ & ${ }^{*} 7.33 \pm 0.61$ & ${ }^{*} 5.33 \pm 0.33$ & ${ }^{*} 4.36 \pm 0.42$ & ${ }^{*} 3.33 \pm 0.64$ & ${ }^{*} 3.12 \pm 0.26$ \\
\hline $\mathrm{R}-7$ & ${ }^{*} 22.5 \pm 0.57$ & ${ }^{*} 15.0 \pm 0.23$ & ${ }^{*} 9.3 \pm 0.15$ & ${ }^{*} 6.9 \pm 0.29$ & ${ }^{*} 5.5 \pm 0.32$ & ${ }^{*} 3.2 \pm 0.12$ & ${ }^{*} 3.5 \pm 0.14$ \\
\hline$R-8$ & ${ }^{*} 20.9 \pm 0.67$ & ${ }^{*} 11.4 \pm 0.41$ & ${ }^{*} 10.2 \pm 0.18$ & ${ }^{*} 7.4 \pm 0.28$ & ${ }^{*} 5.6 \pm 0.74$ & ${ }^{*} 4.4 \pm 0.54$ & ${ }^{*} 3.5 \pm 0.28$ \\
\hline
\end{tabular}

*Statistically significant difference with respect to week 0 , ANOVA and Student T test, $p=<0.005$; The frequency of erythrocytes was counted in 3000 cells per rat.

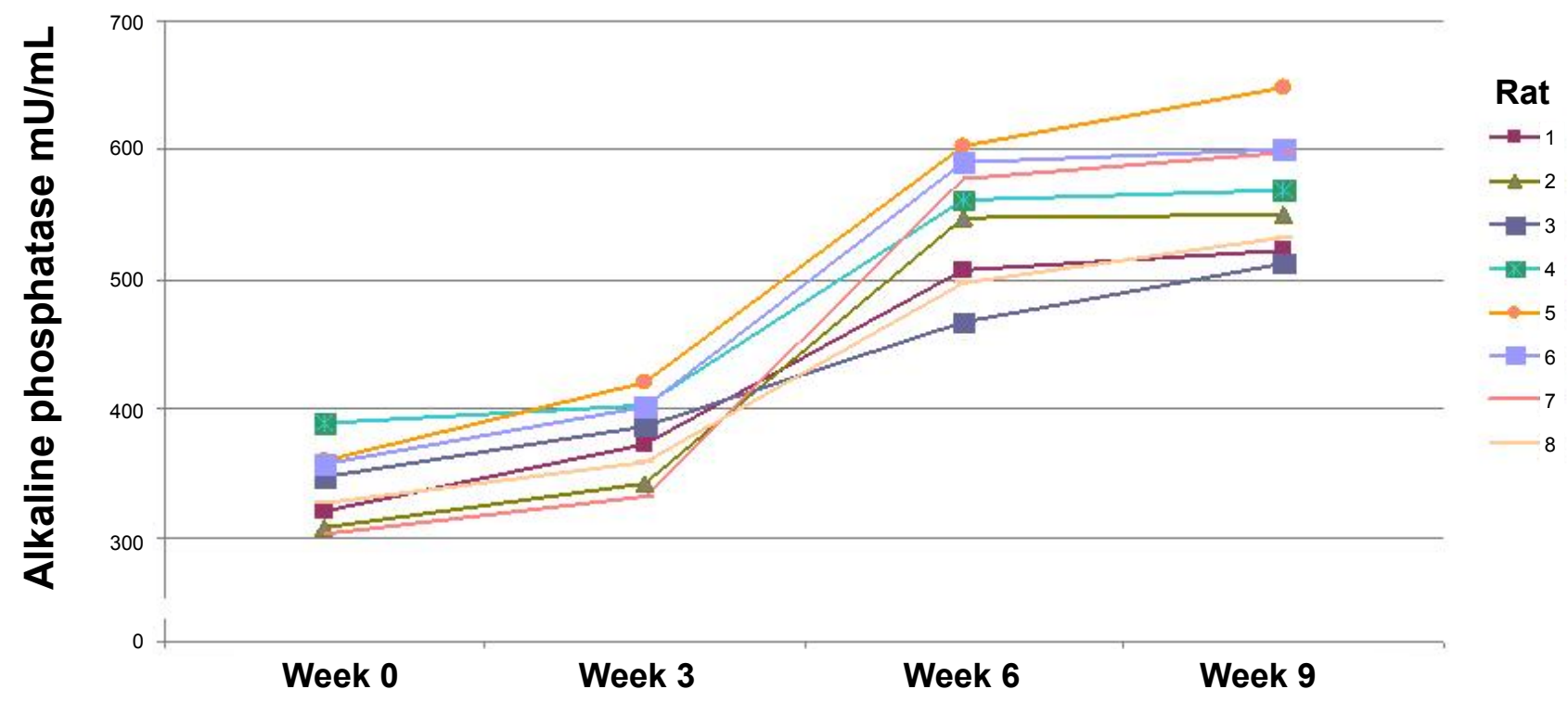

Graph 2: Serum alkaline phosphatase levels in rats treated with benzopyrene.

*Statistically significant difference with respect to week 0, ANOVA and Student T test, $p=<0.05$.

The values correspond to $\mathrm{mU} / \mathrm{mL}$ of $\mathrm{AF}$. 


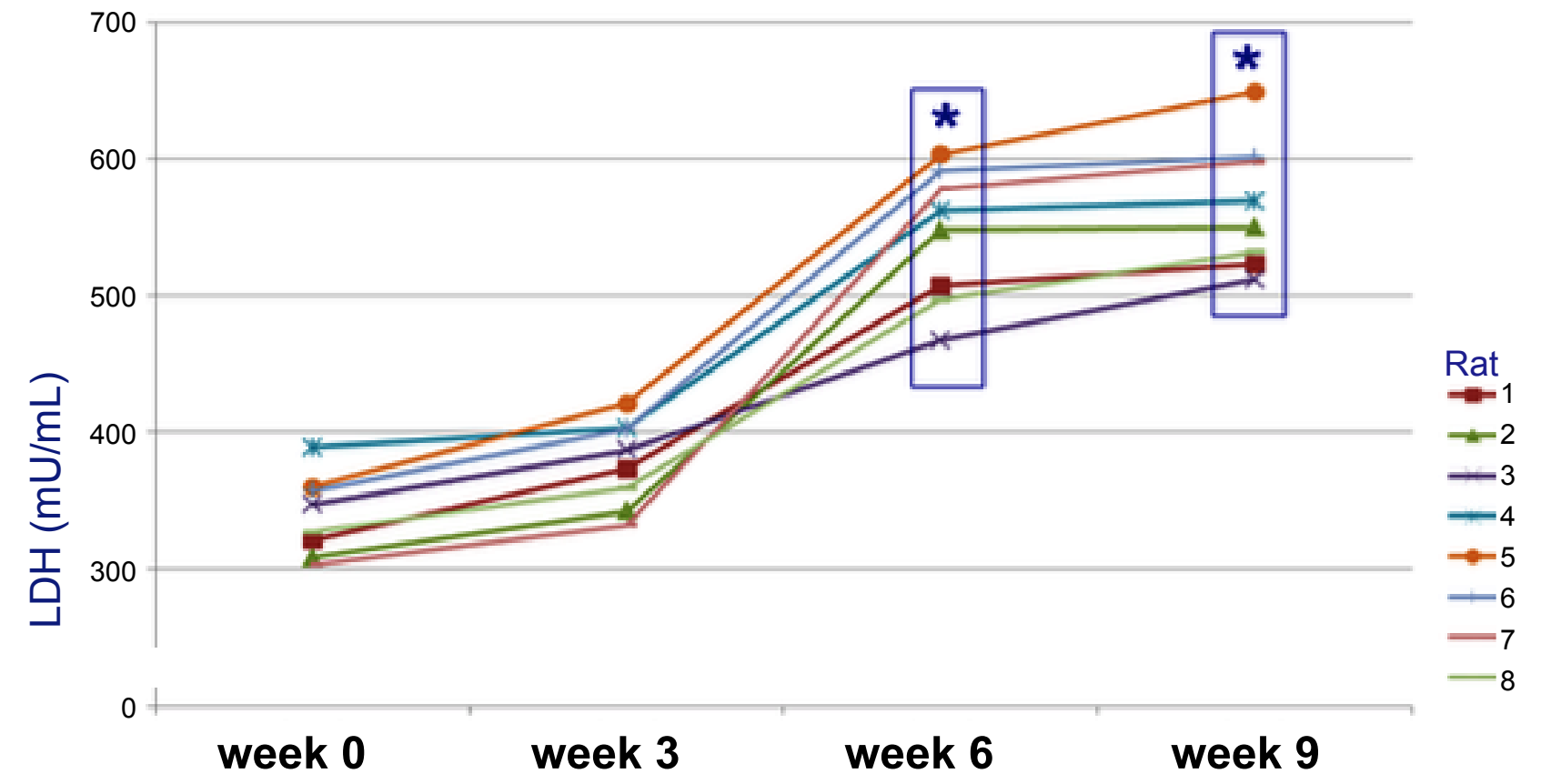

Graph 3: Blood levels of lactato dehydrogenase (LDH) in rats treated with benzopyrene.

*Statistically significant difference with respect to week 0 , ANOVA and Student T test, $p=<0.05$.

The values correspond to $\mathrm{mU} / \mathrm{mL}$ of $\mathrm{AF}$.

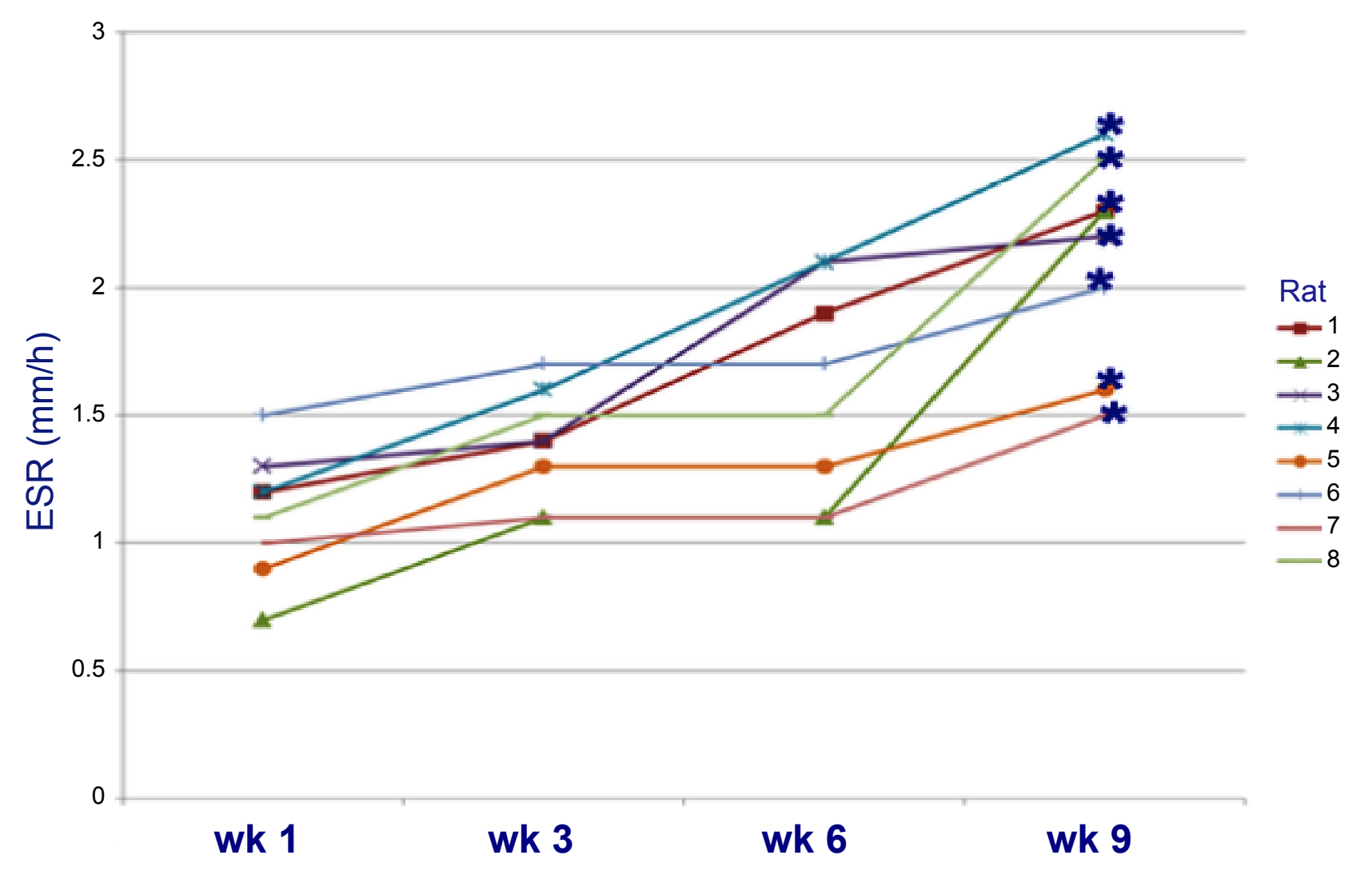

Graph 4: Erythrocyte sedimentation rate (ESR) in rats treated whit benzopyrene.

*Statistically significant difference with respect to week 0 , ANOVA and Student T test, $p=<0.05$.

The values correspond to $\mathrm{mm} / \mathrm{h}$. 


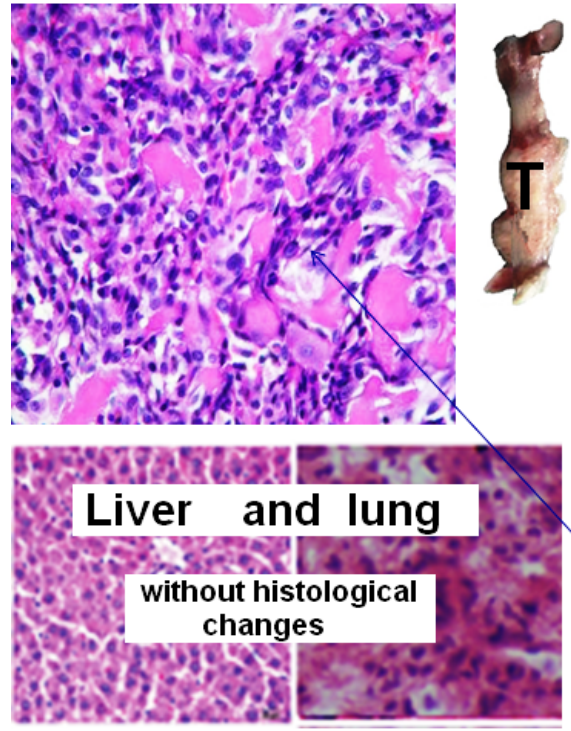

Femur right, without
histological changes

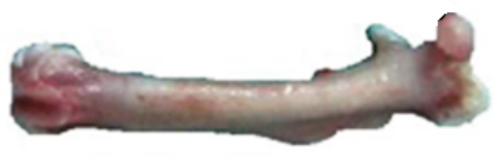

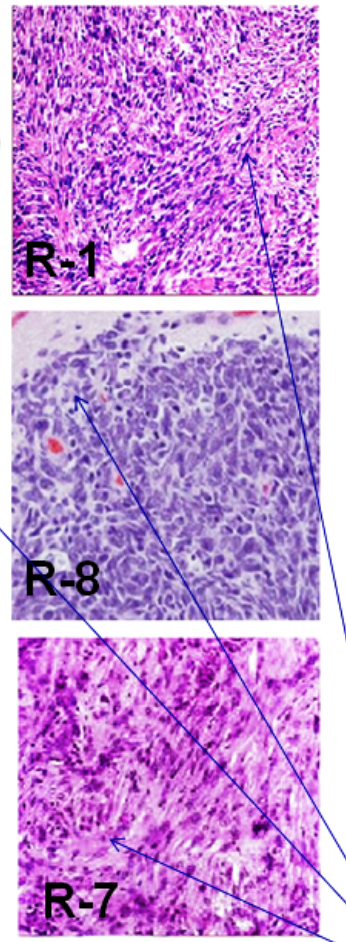
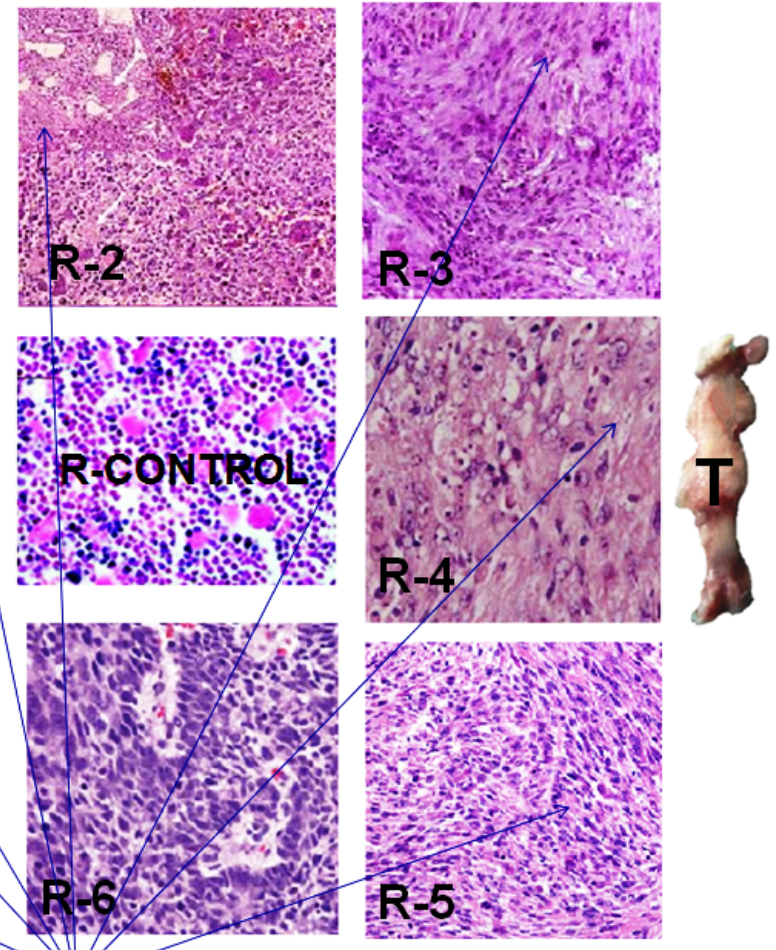

\section{Dense population of spindle cells, with production of nuclear atypia and osteoid tissue}

Figure 1: Histological study in rats $(\mathrm{R})$ treated with benzopyrene.

The study showed the presence of cellular and osteoid atypia in all treated rats (R-1 to R-8), and the formation of tumors ( $T$ ) in the femur administered with BZP. Liver and lung showed no histological changes.

BZP has been classified as a reproductive toxicant that affects fertility in rats and other animal species, because the resulting metabolites interfere with the normal function of the ovary [26]. Tsai-Turton, et al. [27], in 2007, evaluated the accumulation of BZP metabolites in liver and testis microsomes of rats, hamsters and pigs, finding that several of these interfere with the formation and function of the gametes, contributing well to infertility. In liver and ovarian cell tissues of several species (rats, mice, goats, sheep, pigs and cows) it was observed that when exposed to $5 \mu \mathrm{g} / \mathrm{g}$ of BZP the resulting metabolites adhere to the estrogen receptor, reducing the activity of these; prolonged exposure to BZP causes a sequestration of these in the high density lipoproteins that are essential for steroid hormone biosynthesis in the ovary, leading to the reduction of gonadotropin secretion, such as follicle stimulating hormone (FSH) and hormone luteinizing (LH), with negative results in the final stages of follicular development, decreasing fertility $[28,29]$. BZP has been reported as a potent inducer of OS, with characteristics similar to the pathophysiology of OS in humans and survival is up to 8 months in treated animals [14]. Given the carcinogenic and mutagenic effects of Benzopyrene, we propose this compound as a chemical substance to induce osteosarcoma in Sprague Dawlwy rats.

Wester and colleagues [30], demonstrated the carcinogenic potential of oral administration of BZP, these researchers exposed 104 Wistar rats for five days a week at amounts of $0,3,10$ or 30 mg of BZP per kg of body weight, for two years and later they carried out histopathological studies. The results showed the development of tumors in the liver in 99 of the 104 rats, with an estimated dose of $3-5 \mathrm{mg} / \mathrm{kg}$, with a confidence interval of $90 \%$ in the same way they showed sarcomas in soft tissues, such as skin and breasts with a dose of $10 \mathrm{mg} / \mathrm{kg}$. Both skin and liver tumors were considered relevant for humans in high doses. The researchers were also able to detect tumors in the small intestine in 13 rats, which should be considered relevant for humans, due to the local activity of the benzopyrenes in the intestine. It was concluded that exposure to $3 \mathrm{mg}$ of BZP per kg of weight orally increases the risk of cancer. Other animal studies have shown that PAH can cause cancer in the lung [31-33] skin, bladder, [34,35] as well as in the esophagus and stomach [36]. Ozaki, et al. [37] evaluated the effect of BZP on the cervical tissue of female rats, which were administered concentrations of 2.5; 5 and 10 $\mathrm{mg} / \mathrm{kg}$ of said compound, dissolved in sesame oil orally and administered peritoneally for a period of 14 weeks and compared them with a group of control female rats who did not have any type of administration and a group called vehicle that only received the administration of sesame oil. Finally, it has been shown that treatment with BZP results in a toxic effect on the cervix. BZP appears to have the potential to cause mutation of the p53 gene in the cervix of mice. 
Citation: Paniagua PR, Franco BR, Madrigal BE, et al. (2019) Induction of Osteosarcoma and Biochemical Effects in Rats Treated with Benzopyrene. J Orthop Rheumatism 3(1):62-70

The results suggest that BZP can lead to the breaking of a strand of DNA or induce mutations, both events being able to inactivate tumor suppressor genes, such as the p53 gene [37], and it has been shown that a decrease in the function of this gene can result in a broad spectrum of malignancies.

\section{Conflict of Interest Declaration}

The authors of this manuscript we have no conflict of interest to declare.

\section{References}

1. Mirabello L, Troisi RJ, Savage SA (2009) Osteosarcoma incidence and survival rates from 1973 to 2004: Data from the Surveillance, Epidemiology, and End Results Program. Cancer 115: 1531.

2. Harrison DJ, Geller DS, Gill JD, et al. (2018) Current and future therapeutic approaches for osteosarcoma. Expert Rev Anticancer Ther 18: 39-50.

3. Anderson ME (2016) Update on survival in osteosarcoma. Orthop Clin North Am 47: 283-292.

4. Mirabello L, Troisi RJ, Savage SA (2009) International osteosarcoma incidence patterns in children and adolescents, middle ages and elderly persons. Int J Cancer 125: 229-234.

5. Morrow JJ, Khanna C (2015) Osteosarcoma genetics and epigenetics: emerging biology and candidate therapies. Crit Rev Oncog 20: 173-197.

6. Anninga JK, Gelderblom H, Fiocco M, et al. (2011) Chemotherapeutic adjuvant treatment for osteosarcoma: where do we stand? Eur J Cancer 47: 2431.

7. Aljubran AH, Griffin A, Pintilie M, et al. (2009) Osteosarcoma in adolescents and adults: survival analysis with and without lung metastases. Ann Oncol 20: 1136.

8. Ottaviano L, Schaefer KL, Gajewski M, et al. (2010) Molecular characterization of commonly used cell lines for bone tumor research: a trans-European EuroBoNet effort. Genes Chromosomes and Cancer 49: 40-51.

9. Ek ET, Dass CR, Choong PF (2006) Commonly used mouse models of osteosarcoma. Critical Reviews in Oncology/Hematology 60: 1-8.

10. Mohseny AB, Machado I, Cai Y, et al. (2011) Functional characterization of osteosarcoma cell lines provides representative models to study the human disease. Laboratory Investigation 91: 1195-1205.

11. Mestas J, Hughes CC (2004) Of mice and not men: Differences between mouse and human immunology. Journal of immunology 172: 2731-2738.

12. Wong VW, Sorkin M, Glotzbach JP, et al. (2011) Surgical approaches to create murine models of human wound healing. $J$ Biomed Biotechnol 2011: 969618.

13. Volk SW, Bohling MW (2013) Comparative wound healing--are the small animal veterinarian's clinical patients an improved translational model for human wound healing research? Wound Repair Regen 21: 372-381.

14. Brunschwing, AD Bissell (1938) Production of osteosarcoma in a mouse by the intramedullary injection of 1,2-benzpyrene. Archives of Surgery 36.

15. Akeda K, Nishimura A, Satonaka H, et al. (2009) Three-dimen- sional alginate spheroid culture system of murine osteosarcoma. Oncology Reports 22: 997-1003.

16. Baker JR (1946) Cytological Technique. Methuen, London.

17. Liu Z, Wang J, Yin P, et al. (2009) RGD-fasl induces apoptosis in hepatocellular carcinoma. Cell Mol Immunol 6: 285-293.

18. Zurera L, Canis M, Marchal T, (2008) Histological study of the effect of pre-transplant chemoembolization of hepatocellular carcinoma. Radiología 50: 47-53.

19. IARC Working Group on the Evaluation of Carcinogenic Risks to Humans (2010) Some non-heterocyclic polycyclic aromatic hydrocarbons and some related exposures. IARC Monogr Eval Carcinog Risks Hum 92: 1-853.

20. Salehi F, Turner MC, Phillips KP, et al. (2008) Review of the etiology of breast cancer with special attention to organochlorines as potential endocrine disruptors. J Toxicol Environ Health B Crit Rev 11: 276-300.

21. Lawal AT (2017) Polycyclic aromatic hydrocarbons. A review. Cogent Environmental Science 3.

22. Ahrendt SA, Decker PA, Alawi EA, et al. (2001) Cigarette smoking is strongly associated with mutation of the K-ras gene in patients with primary adenocarcinoma of the lung. Cancer 92: 15251530.

23. Barnes DW, Carr TE, Evans EP, et al. (1970) 90Sr-induced osteosarcomas in radiation chimaeras. Int J Radiat Biol 18: 531537.

24. Heddle JA, Cimino MC, Hayashi M, et al. (1991) Micronuclei as an Index of Cytogenetic Damage: Past, Present, and Future. Environm Molec Mut 18: 277-290.

25. Paniagua-Pérez R, Madrigal-Bujaidar E, Reyes-Cadena $S$, et al. (2008) Cell protection induced by beta-sitosterol: inhibition of genotoxic damage, stimulation of lymphocyte production, and determination of its antioxidant capacity. Arch Toxicol 103: 569573.

26. (2008) Polycyclic Aromatic Hydrocarbons in Food [1] - Scientific Opinion of the Panel on Contaminants in the Food Chain. EFSA J 724: 2-114.

27. Tsai-Turton $M$, Nakamura BN, Luderer $U$ (2007) Induction of apoptosis by 9,10 -dimethyl-1,2-benzanthracene in cultured preovulatory rat follicles is preceded by a rise in reactive oxygen species and is prevented by glutathione. Biol Reprod 77: 442451.

28. Smith TL, Merry ST, Harris DL, et al. (2007) Species-specific testicular and hepatic microsomal metabolism of benzo(a) pyrene, an ubiquitous toxicant and endocrine disruptor. Toxicol In Vitro 21: 753-758.

29. Harris DL, Huderson AC, Niaz MS, et al. (2009) Comparative metabolism of benzo(a)pyrene by ovarian microsomes of various species. Environ Toxicol 24: 603-609.

30. Wester PW, Muller JJ, Slob W, et al. (2012) Carcinogenic activity of benzo[a]pyrene in a 2 year oral study in Wistar rats. Food Chem Toxicol 50: 927-935.

31. Shimada T (2006) Xenobiotic-metabolizing enzymes involved in activation and detoxification of carcinogenic polycyclic aromatic hydrocarbons. Drug Metab Pharmacokinet 21: 257-276.

32. Simko $P$ (2002) Determination of polycyclic aromatic hydrocarbons in smoked meat products and smoke flavouring food additives. J Chromatogr B Analyt Technol Biomed Life Sci 770: 3-18. 
Citation: Paniagua PR, Franco BR, Madrigal BE, et al. (2019) Induction of Osteosarcoma and Biochemical Effects in Rats Treated with Benzopyrene. J Orthop Rheumatism 3(1):62-70

33. Miranda CL, Chung WG, Wang-Buhler JL, et al. (2006) Comparative in vitro metabolism of benzo[a]pyrene by recombinant zebrafish CYP1A and liver microsomes from beta-naphthoflavone-treated rainbow trout. Aquat Toxicol 80: 101-108.

34. Sang H, Zhang L, Li J (2012) Anti-benzopyrene-7,8-diol-9,10epoxide induces apoptosis via mitochondrial pathway in human bronchiolar epithelium cells independent of the mitochondria permeability transition pore. Food Chem Toxicol 50: 2417-2423.
35. Compagnone D, Curini R, D'Ascenzo G, et al. (2011) Neutral loss and precursor ion scan tandem mass spectrometry for study of activated benzopyrene-DNA adducts. Anal Bioanal Chem 401: 1983-1991.

36. Culp SJ, Gaylor DW, Sheldon WG, et al. (1998) A comparison of the tumors induced by coal tar and benzo[a]pyrene in a 2-year bioassay. Carcinogenesis 19: 117-124.

37. Ozaki T, Nakagawara A (2010) p53: the attractive tumor suppressor in the cancer research field. J Biomed Biotechnol 2011. 